\title{
A challenging case of esophageal perforation
}

\author{
Kamal Kant Sahu, Ajay Kumar Mishra, Ruchita Patel, Nuttanun Suramaethakul \\ Department of Internal Medicine, Saint Vincent Hospital, Worcester, MA, USA
}

\begin{abstract}
Esophageal perforation is a fatal entity if not diagnosed in a timely fashion. Once diagnosed, it requires collaborative effort of team of doctors including radiologists, thoracic surgeons and general surgeons. We share hereby our experience with esophageal perforation and successful outcome.
\end{abstract}

\section{Case Report}

A 68-year-old gentleman was admitted to the hospital with nausea and vomiting following binge alcohol drinking. He was suspected to have aspiration pneumonia due to fever and hypoxia. Chest X ray followed by CT Chest was done which revealed contained loculated thick-walled bilateral pleural collections with airfluid levels and frothy secretions/debris communicating with the posterior mediastinum surrounding the esophagus (Figure 1). This was most likely in keeping with contained esophageal perforation with associated collection. Fluoroscopy using the gastrografin was done to confirm the site of leak (Figure 1). There was leaking of

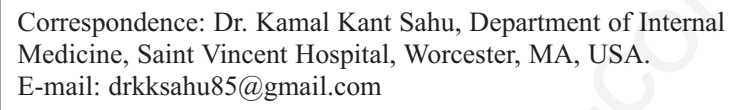

Conflict of interest: The authors declare that they have no competing interests, and all authors confirm accuracy.

Ethics approval: The article does not contain participation of any human being and animal.

Contributions: All the authors played a significant role in the paper. All the authors have read and approved the final version of the manuscript and agreed to be accountable for all aspects of the work.

IRB approval: Not applicable.

Key words: Esophageal perforation, mediastinum, endoscopy

Received for publication: 8 June 2020 .

Accepted for publication: 14 October 2020.

${ }^{\circ}$ Copyright: the Author(s), 2021

Licensee PAGEPress, Italy

Monaldi Archives for Chest Disease 2021; 91:1443

doi: 10.4081/monaldi.2021.1443

This article is distributed under the terms of the Creative Commons Attribution Noncommercial License (by-nc 4.0) which permits any noncommercial use, distribution, and reproduction in any medium, provided the original author(s) and source are credited. contrast material out of the mid to distal esophagus at the junction of the middle third with the distal third, the likely site of esophageal perforation. Leakage of contrast was seen both along the right and left aspects of the esophagus and appeared contained. Surgical team was involved, however patient denied surgery initially only to agree later. After $48 \mathrm{~h}$ of initial diagnosis, patient underwent bilateral posterolateral thoracotomy, extensive intrapleural pneumonolysis, drainage of mediastinal abscess, identification of esophageal perforation, debridement of necrotic mediastinal and esophageal tissue, removal of intrapleural fibrin deposits, and total pulmonary decortication. On each side, a large 32 french regular argyle chest tube was placed. This was followed by flexible esophagoscopy on the $3^{\text {rd }}$ day and placement of a $23 \mathrm{x}$ $150 \mathrm{~mm}$ esophageal stent. A follow up CT imaging shows resolution of effusion and sealing of perforation (Figure 2). Patient required prolonged duration of ICU stay for almost 3 weeks.

\section{Discussion}

Esophageal perforation is extremely rare and life-threatening emergency. Recent series have reported high mortality up to $20 \%$. Spontaneous rupture constitutes approximately $1 / 3^{\text {rd }}$ of the esophageal perforations. Most cardinal symptom is chest pain and in combination with vomiting and subcutaneous emphysema, constitutes as Mackler's triad. In our case, retching secondary to alcohol induced gastritis was the probable cause of perforation.

A plain X ray could provide important radiological evidence like pleural effusion, pneumomediastinum, hydropneumothorax etc. CT chest and fluoroscopy detect the perforation and site of leak in most cases. In our case also, CT picked the diagnosis and was subsequently confirmed with positive leak of gastrografin in fluoroscopy. Recently, flexible esophagoscopy (FE) has been increasingly used when suspicion is high and radiological imaging are inconclusive. Arantes et al. in their retrospective study of 139 patients found FE to be an accurate tool with $95.8 \%$ sensitivity and $99.3 \%$ specificity [1]. FE has the advantage of direct visualization of the lesions. Arantes et al. divided the lesions into 2 major categories: laceration and contusion. While laceration requires either primary surgical repair or esophageal stent placement, contusion can be followed conservatively with repeat imaging.

Thoracic surgeons are increasingly preferring non-operative measures by using temporary endoscopic esophageal stents. Anastomotic insufficiencies can also result in esophageal defects and perforations. Loske et al. successful use of endoscopic vacuum sponge in their series of 10 cases [2].

In conclusion, esophageal perforation is a rare entity. Timely diagnosis of esophageal perforation and similar pathologies is the most crucial in management $[3,4]$. Nonspecific symptoms make suspicion even more difficult. Current recommendations regarding treatment is based on institutional series and experiences. 

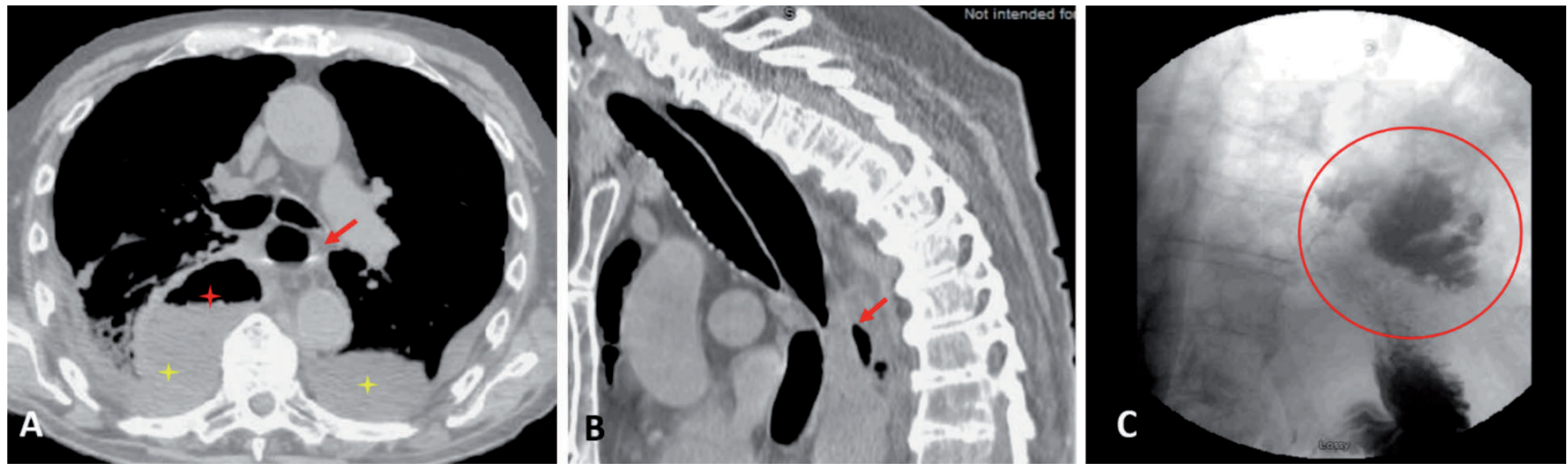

Figure 1. A) CT chest axial view showing air in esophagus (red arrow), bilateral pleural effusion (yellow stars) with contained collection with air fluid level (red star). B) CT chest sagittal view showing air in the posterior mediastinum (red arrow). C) Fluoroscopy which shows active leak of gastrografin from mid to distal esophagus into mediastinum.
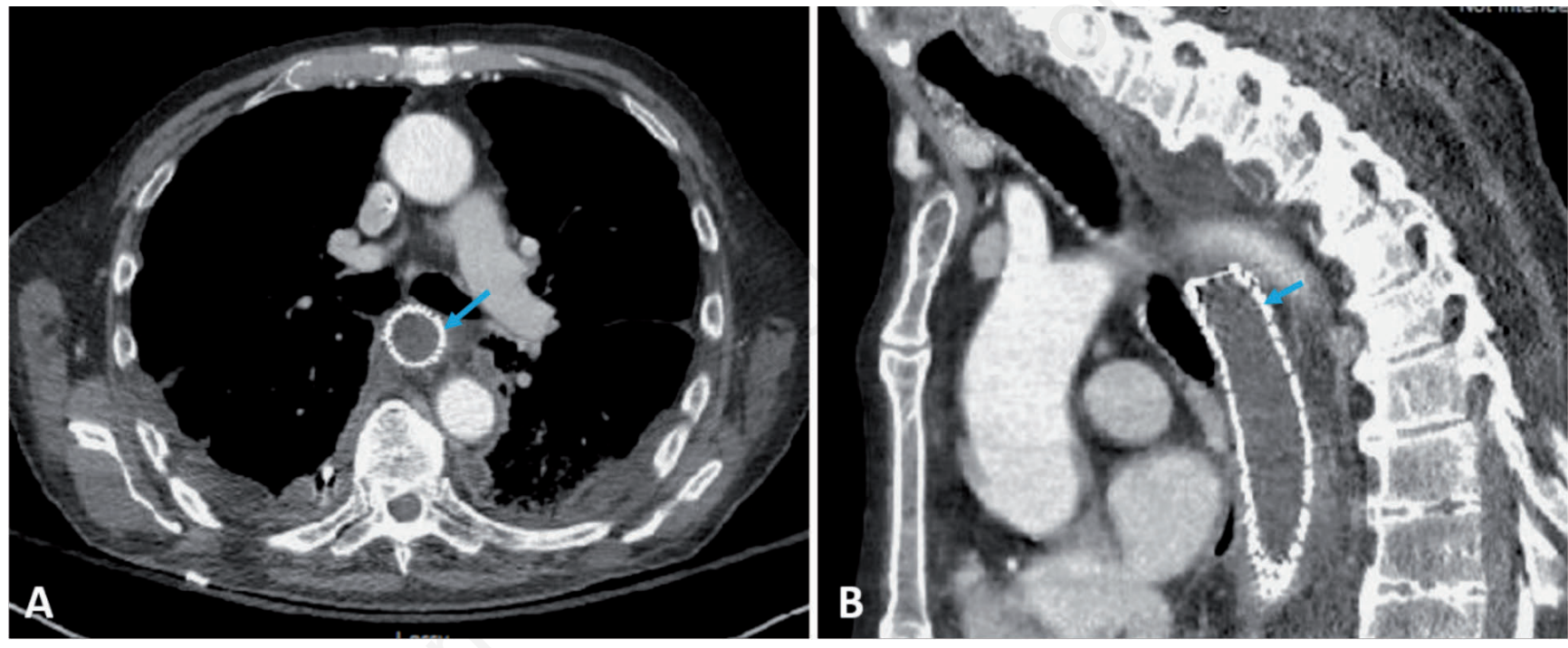

Figure 2. Axial (A) and sagittal (B) view. Comparative scan after 10 days of procedure showing resolution of effusion and presence of esophageal stent (blue arrow).

\section{References}

Arantes V, Campolina C, Valerio SH, et al. Flexible esophagoscopy as a diagnostic tool for traumatic esophageal injuries. J Trauma 2009;66:1677-82.

Loske G, Schorsch T, Müller C. Endoscopic vacuum sponge ther- apy for esophageal defects. Surg Endosc 2010;24:2531-5. Sahu KK, Sherif AA, Mishra AK, et al. Perineal ulcer: a rare cause of extensive subcutaneous emphysema. BMJ Case Rep 2019; 12:e229918.

Sahu KK, Badhala P, Malhotra P, Aggarwal AN. A rare case of rituximab induced interstitial lung disease. Lung India 2016;33:472-3. 